\title{
Beta-adrenergic antagonist for the healing of chronic diabetic foot ulcers: study protocol for a prospective, randomized, double-blinded, controlled and parallel- group study
}

Ramanjot Kaur ${ }^{1,2}$, Catherine Tchanque-Fossuo 1,2, Kaitlyn West ${ }^{1,3}$, Yasmin Hadian ${ }^{1,2}$, Anthony Gallegos², Daniel Yoon ${ }^{1,2}$, Ligia Ismailyan ${ }^{1}$, Saul Schaefer ${ }^{4}$, Sara E. Dahle ${ }^{2,3^{*}}$ (i) and R. Rivkah Isseroff f, $^{1 *}$

\begin{abstract}
Background: Diabetic foot ulcers (DFUs) are the most common cause of leg amputations and their management is extremely challenging. Despite many advances and expensive therapies, there has been little success in improving outcomes of DFUs. In prior work our laboratory has examined the effects of beta-adrenergic antagonists (BAAs) on skin and skin-derived cells. We have shown that $\beta A A s$ enhance the rate of keratinocyte migration, promote angiogenesis, and hasten wound healing in scratch wounds in vitro, in animal wound models, and in anecdotally reported cases of chronic wounds that healed successfully after topical application of the $\beta A A$ timolol. Thus, we propose to test timolol directly on DFUs to determine if it improves healing above the current standard of care (SOC). This study will examine the efficacy and safety of topically applied beta-antagonist Timoptic-XE® (timolol maleate ophthalmic gel forming solution) in subjects with DFUs.

Methods/design: This is a phase two, randomized, double-blinded, controlled, and parallel-group clinical trial with two treatment arms, SOC plus topical Timoptic-XE巴 and SOC plus a non-biologically active gel (hydrogel, as placebo drug). Study subjects with a DFU will be selected from the Veterans Affairs Northern California Health Care System (VANCHCS). Study duration is up to 31 weeks, with three phases (screening phase for two weeks, active phase for up to 12 weeks, with an additional second consecutive confirmatory visit after 2 weeks, and follow-up phase comprising monthly visits for 4 months). Subjects will apply daily either the topical study drug or the placebo on the foot ulcer for 12 weeks or until healed, whichever comes first. Measurements of wound size and other data will be collected at baseline, followed by weekly visits for 12 weeks, and then a monthly follow-up period.

(Continued on next page)
\end{abstract}

\footnotetext{
* Correspondence: sara.dahle@va.gov; rrisseroff@ucdavis.edu

${ }^{2}$ Department of Dermatology, UC Davis Medical Center, Sacramento, CA, USA

'Dermatology Service, VA Northern California Health Care System, Mather,

CA, USA

Full list of author information is available at the end of the article
}

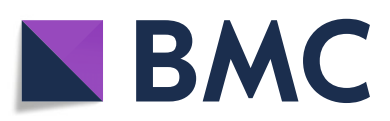

() The Author(s). 2020 Open Access This article is licensed under a Creative Commons Attribution 4.0 International License, which permits use, sharing, adaptation, distribution and reproduction in any medium or format, as long as you give appropriate credit to the original author(s) and the source, provide a link to the Creative Commons licence, and indicate if changes were made. The images or other third party material in this article are included in the article's Creative Commons licence, unless indicated otherwise in a credit line to the material. If material is not included in the article's Creative Commons licence and your intended use is not permitted by statutory regulation or exceeds the permitted use, you will need to obtain permission directly from the copyright holder. To view a copy of this licence, visit http://creativecommons.org/licenses/by/4.0/ The Creative Commons Public Domain Dedication waiver (http://creativecommons.org/publicdomain/zero/1.0/) applies to the data made available in this article, unless otherwise stated in a credit line to the data. 
(Continued from previous page)

Discussion: This is a clinical translation study, moving the investigators' pre-clinical laboratory research into a translational study in which we will analyze clinical outcomes to assess for safety and estimate the efficacy of a topical beta-antagonist in healing of DFUs. The results from this trial may establish new treatment paradigms and safety profile for DFU treatment.

Trial registration: ClinicalTrials.gov, NCT03282981. Registered on June 14th, 2018.

Keywords: Diabetic foot ulcer, Chronic wounds, Nonhealing wounds, Timolol, Randomized controlled trial

\section{Background}

Diabetic foot ulcers (DFUs) account for significant morbidity and immense biomedical burden. Aside from the management of multiorgan comorbidities in diabetic patients, DFUs alone substantially impact our health care system with both economic and psychosocial effects. A diabetic patient has a $25 \%$ lifetime risk of developing a DFU [1]. As the DFU becomes intractable, the patient's quality of life and productivity are considerably affected [1-3]. There is a one in six risk that patients with a DFU will have an amputation, with a $66 \%$ risk of recurrence and a $47 \%$ increase in mortality, as high as colon cancer [3-5]. Notably, according to the US Census Bureau, there are 21.8 million veterans in the US, and nearly $25 \%$ have diabetes compared to $10.5 \%$ of the general population [6-10]. A study involving veterans with diabetes and a foot ulcer noted that there was a 2.39 increased relative risk of death compared to those without a foot ulcer [11]. Preventative measures are taken to reduce the burden of diabetes and aggressive treatment is used for the ulcers before they advance to amputation.

Health care systems invest enormous sums of money in improving the healing of DFUs, with an estimated annual cost for DFU treatment in the US exceeding $\$ 10.9$ billion [12]. Several advanced treatments for DFUs exist, but they are expensive, difficult to use in the clinic or at home, and have shown limited success in the healing of DFUs. The cost per episode of DFU treatment can easily exceed $\$ 38$, 000 plus associated expenses related to hospitalization, ulcer recurrences, amputations, home health care, dressings, decreased productivity and premature disability, social isolation, and depression [1-3, 8, 13].

The standard of care (SOC) for a DFU generally consists of the debridement of necrotic tissue, application of a moist dressing, and the use of offloading devices (such as foot orthoses, total contact cast and/or with the use of crutches, wheelchair, scooter, or other assistive ambulatory devices) that protect the wound from pressure or trauma related to ambulation and other acts of daily living, and management for infection if indicated [2, 3, 13-18]. Nevertheless, despite wound specialists adhering to the best standard wound care regimens, only $31 \%$ of DFUs heal after 20 weeks of care [18, 19]. Such an unfavorable cure rate has prompted increased research for therapeutic alternatives and novel approaches to optimize wound healing, particularly for the growing
Veterans Affairs (VA) diabetic population. Therefore, preventing further complications and the high costs associated with DFU treatment is critical. Thus, we are investigating using a safe, inexpensive, well-characterized, easy to use drug that could be implemented system-wide to enhance DFU repair and may have far-reaching consequences.

In prior work our laboratory has examined the effects of beta-adrenergic antagonists ( $\beta A A)$ on skin and skinderived cells. Of the several classes of adrenergic receptors, predominant expression of the $\beta 2$ subtype has been identified on major cell types of the skin, including human keratinocytes, melanocytes, and dermal fibroblasts [20-23]. Keratinocytes can also synthesize catecholamines such as epinephrine and norepinephrine [20-24], in essence creating a self-contained, catecholamine signaling network. The functional role of this network has been elusive. Our work suggests that it contributes to the control of cell migration, and thus to skin wound healing [25-28].

When skin is wounded, repair mechanisms are activated to restore skin integrity. The repair process involves the orchestration of interactions between cellular components, growth factors, chemokines, and extracellular matrix proteins that regulate the migration and proliferation of the keratinocytes into the wound [2931]. This directional migration of keratinocytes into the wound is critical for repair and reestablishment of epithelial coherence. Our laboratory work has shown that activation of $\beta A R$ by stress-catecholamine agonists, such as epinephrine and norepinephrine, decreases keratinocyte migration, decreases the ability to heal an in vitro scratch wound, and impairs healing of acute wounds in animal models [23, 27, 28, 31-34]. Importantly, these $\beta A R$ agonists are found in significant concentrations in human DFU tissues [28].

The natural corollary to the finding of stress catecholamine $\beta A R$ ligands within the wound environment that can impair pro-reparative functions of skin-derived cells [23-28, 30, 31, 35] was to determine the effects of blocking their action. Importantly, and specifically relevant to our proposed clinical trial, we have shown that blockade of the $\beta A R$ with antagonists improves healing in vitro and in animal models [24, 26, 28]. Work by other investigators also supports the hypothesis that $\beta A R$ antagonists can improve DFU healing. Collagen synthesis (in a 
pulmonary injury model) has been observed to be increased by $\beta A R$ antagonists [36]. More specifically, Gulcan and colleagues demonstrated that the topical application of $\beta A R$ antagonists to wounds in diabetic rats improves not only the rate of healing, but wound vascularity [37]. Indeed, a patent application on the use of a $\beta A R$ antagonist for the healing of DFUs has been filed by other investigators [38], albeit with no human clinical data. Our goal with this clinical trial is to generate these unequivocal data and to demonstrate the safety and efficacy of this approach to improve healing in human chronic DFUs.

Here we propose a clinical translational study, moving our original laboratory research into an early clinical trial to test this hypothesis. Therefore, the main aim of this proposal is to establish timolol ((S)-1-[(1,1-dimethylethyl)amino]-3-[[4-(4-morpholiny)-1,2,5-thiadiazol-3-

yl]oxy]-2-propanol (Z)-2-butenedioate(1:1) (salt)), a nonselective beta-adrenergic antagonist, as a novel therapeutic alternative in response to the challenging clinical management of DFUs. We expect this study will demonstrate that timolol, a low-cost therapy, improves the rate of wound healing, which in turn will have tremendous long-term benefits, improving morbidity, quality of life, as well as the negative psychological and social issues associated with DFUs.

\section{Methods/design \\ Design}

We propose a phase 2, randomized, double-blinded, controlled, and parallel-group clinical trial to assess the effectiveness of topical timolol (SOC plus topical Timoptic- $\mathrm{XE}^{\circ}$ ) compared to standard of care (SOC; plus a non-biologically active gel, hydrogel) on DFUs.

\section{Study objectives}

Our primary objective is to test the hypothesis that topically applied timolol can significantly increase complete ulcer healing within 12 weeks.

Our secondary objective is to assess the safety profile of topically applied timolol in the treatment of DFUs. Building on the excellent safety record of timolol in various topical applications, we will measure the timolol plasma levels during the treatment phase and the rate of adverse events in the setting of a randomized controlled trial.

Other secondary objectives are to measure the following: comparison of two study arms for percentage difference in change in size from randomization visit to the endpoint visit (post 12 weeks), the time to wound closure between the two groups, and wound healing rates in comparison with wound size between the treatment groups; in addition, quality of life using Veterans Rand (VR-36) Health Survey and the Lower Extremity Functional Scale, and the measurement of all the adverse events associated with the use of timolol.

\section{Study description \\ Study population}

This study will be conducted exclusively on veterans who are 18 years of age or older, with a documented diagnosis of diabetes and foot ulceration that has been present for at least 4 weeks. The study protocol is approved by both the Veterans Affairs' Research and Development Committee and their Institutional Review Board (IRB). The study site is at the main campus, located at the Sacramento VA Medical center, which houses a comprehensive multi-specialty wound clinic. We will recruit patients from this wound clinic as well as from the other six surrounding satellite clinic sites of the VA Northern California Health Care System (VANCHCS). The multi-specialty wound clinic is staffed by dermatologists, podiatrists, a wound/ostomy nurse, and a vascular interventional radiologist. All recruited patients will be seen at this single, multi-specialty wound clinic which treats a variety of wounds, including diabetic, venous, and pressure ulcers. With approximately 1002 patients treated for DFUs in the past year at VANCHCS alone, we have a strong clinical base from which to recruit for this study. This does not include referrals that we anticipate from the primary care, vascular, podiatry and dermatology clinics from the six other satellite clinics within VANCHCS.

The study will consist of volunteer patients who have diabetes mellitus documented using the criteria of the American Diabetes Association, who have a foot ulcer below the malleolus. The DFU must be at least 4 weeks old with a surface area between $0.5-20 \mathrm{~cm}^{2}$ after debridement, with no active infection, including cellulitis or osteomyelitis, as listed in Table 1. Subjects who meet the inclusion and exclusion criteria will be randomized to either group A ( $\beta A R$ antagonist group plus SOC) or group B (non-biologically active gel plus SOC). Patients in either group will receive the once-daily application of the study drug for 12 weeks or until the ulcer heals, whichever comes first.

\section{Study framework}

The maximum study duration is 31 weeks, with three phases, described in Fig. 1. The initial two weeks (visits $1-2 /$ weeks 1-2) will consist of the screening phase, followed by 12 weeks (visits 3-15/weeks 3-15) of the active phase. If the DFU wound heals, the active phase also includes two confirmatory visits for 2 weeks. The final phase, follow-up phase, will consist of monthly clinic visits for 4 months (visits 16-19/weeks 19-31; Fig. 2).

The study is powered to determine outcomes with 138 patients to accommodate anticipated withdrawals to achieve enrollment of 48 patients, 24 per arm. Figure 3 
Table 1 Inclusion and exclusion criteria

\section{Inclusion criteria \\ - Have diagnosis of diabetes mellitus \\ - Male or female subject of any race aged 18 years or older \\ - Lower extremity ulcer located anywhere on the foot up to the ankle \\ - Of more than 30 days duration and less than 2 years duration (medically documented) \\ - Surface area between $0.5 \mathrm{~cm}^{2}$ and $20 \mathrm{~cm}^{2}$ (as measured with the Silhouette imaging system at randomization). The ulcer with largest surface area meeting inclusion criteria will be selected as the index ulcer \\ - If two ulcers are present with the same surface area, the ulcer of the longest duration will be selected as the index ulcer \\ - Documented ankle-brachial index (ABI) between 0.8 and 1.2 on the study limb or toe pressure over $65 \mathrm{mmHg}$ within 6 months of screening phase \\ - Documented biopsy report to rule out malignancy of ulcer of $>6$ months' duration}

\section{Exclusion criteria}

- Ulcer of non-diabetic etiology, such as venous, arterial, and burn wounds

- Index ulcer is less than $3 \mathrm{~cm}$ in distance from any other ulcer on the same extremity

- There are more than three ulcers on the study foot

- Index ulcer presents with any of the following: cellulitis, osteomyelitis, exposed bone, tendon or fascia, purulent exudates, or gangrene

- Index ulcer shows evidence of infection (defined as a moderate or severe rating of all of the following clinical signs/symptoms: 1) increased warmth, 2) increased pain, 3) erythema, and 4) malodorous exudate at screening or at randomization (visit 1), OR total organism count $>1 \times 10^{5}$ colony forming units (CFU) from the screening visit study ulcer culture sample)

- Index ulcer surface area has decreased or increased $>40 \%$ between screening and at randomization (visit 1) as assessed by the Silhouette imaging system

- Has medically documented history of HIV

- Has active malignancy on the study limb

- Has uncontrolled diabetes mellitus as defined by glycosylated hemoglobin A1C > 12\% within 3 months of screening

- Has immunodeficiency as defined by serum lgG, IgA, and lgM less than one-half the lower limit of normal

- Has severe protein malnutrition as defined by serum albumin $<2.5$ $\mathrm{g} / \mathrm{dL}$

- Has chronic renal insufficiency requiring dialysis

- Has serum aspartate aminotransferase (AST, SGOT, GOT) or serum alanine aminotransferase (ALT, SGPT, GPT) levels greater than twice the upper limit of normal

- Has fatigue, palpitations, dyspnea, and/or angina at rest

- Has a medically documented or self-reported history, within the previous 12 months from date of screening visit, of alcohol or drug abuse, particularly methadone or heroin

- Has received previous treatment with the following during the 60 days prior to screening: immunosuppressive agents, radiation, chemotherapy, growth factors (epidermal growth factor, tumor necrosis factor, transforming growth factor, platelet derived growth
Table 1 Inclusion and exclusion criteria (Continued)

factor, etc.) at the site of the study ulcer, split- or full-thickness skin graft at the site of the study ulcer, biologically active (or engineered) cellular or acellular product(s) at the site of the study ulcer, investigational drug or device

- Has been hospitalized for treatment of a diabetic foot ulcer within the previous 30 days from screening

- Has history of bradycardia (heart rate less than 60)

- Has ESR $>70 \mathrm{~mm} / \mathrm{h}$ and CRP $>100 \mathrm{mg} / \mathrm{L}$ at time of screening

- Has medically documented history of hypotension/orthostatic hypotension and/or symptomatic hypotension (systolic blood pressure below 90 and diastolic blood pressure less than 60). (Note that there is no standard testing regimen protocol for orthostatic hypotension, even for patients starting on oral timolol)

- Currently taking asthma or COPD medications (as documented in chart)

- Has a medically documented diagnosis of myasthenia gravis, untreated hyperthyroidism, type 1 and/or type 2 heart block

- Female who is pregnant or refuses to use adequate contraceptive methods and is of childbearing age during the trial

- Prisoners, institutionalized individuals, or vulnerable population

illustrates the selection process with the expected number of participants in the study. With a minimum of $60 \%$ participation, there should be adequate recruitment for this study. Thus, we will accrue a total target sample of approximately 138 subjects. Of these subjects, we estimate an overall $35 \%$ withdrawal/dropout rate for a total of 48 enrolled subjects (24 patients per arm). This includes the presumed $10 \%$ of enrolled subjects who will be exited from the study prior to randomization, the $10 \%$ who will not meet the primary endpoint analysis inclusion requirement, and the $15 \%$ who will not complete the study due to other factors such as treatment failure, loss to follow-up, adverse events, clinical/safety issues, and/or non-compliance.

\section{Data collection}

The research team, including the principle investigators, will gather the data. Ulcer area measurements will be conducted using the Silhouette ${ }^{\bullet}$ Aranz 3D-digital photography system, pre- and post-debridement of ulcers, along with physical examination and patient documentation of each research visit.

Ulcer measures will be collected at baseline and weekly after that until the completion of the study. The primary endpoint will be obtained at visit 15/week 15, and the final secondary endpoint measurement collected at visit 19/ week 31 . The area of the target ulcer will be summarized by treatment group and research visits. Both actual value and change of the ulcer area from the previous visit will be calculated, as will changes from baseline, which quantify the weekly changes and the weekly percentage change in the target ulcer area from visit to visit. 


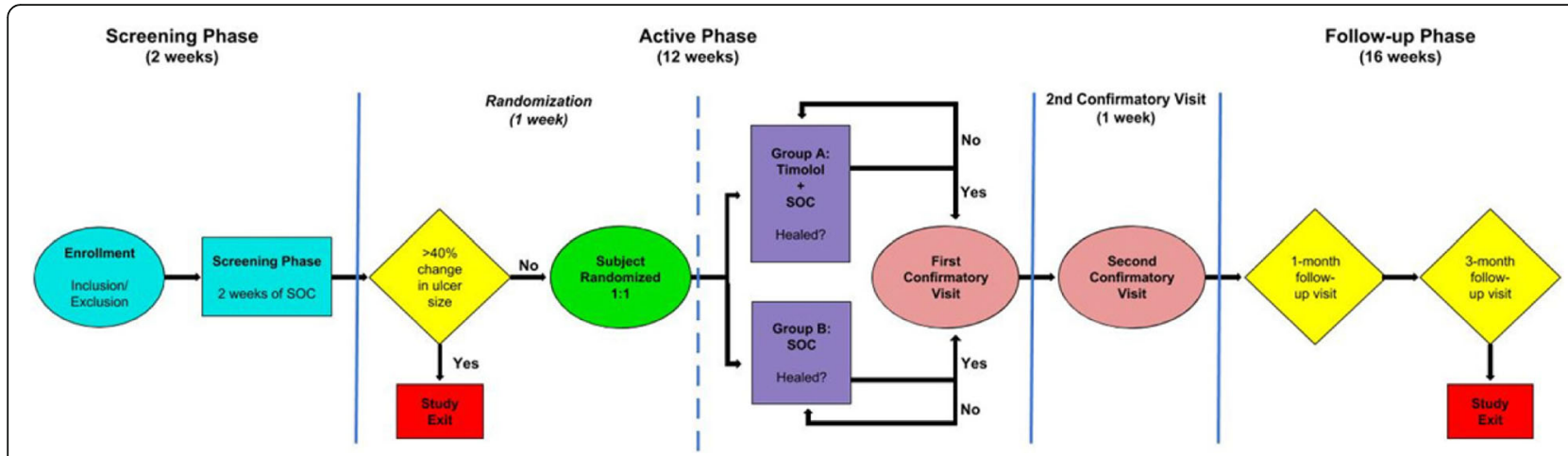

Fig. 1 Study timeline

Primary analyses will evaluate ulcer healing rates, defined as "skin re-epithelialization without drainage and dressing requirement" by week 12 (end of the active phase of the study). The secondary analyses to evaluate the association of specific wound characteristics (such as change in wound size over time, wound location) and subject characteristics (body mass index, chronicity of the wound, years of diabetes diagnosis, $\mathrm{HbA1c}$, and $\mathrm{ABI} /$ toe pressure) will be conducted using logistic regression. Additional logistic regression analysis will be applied to investigate the relationship between the occurrence of each type of adverse event and treatment in order to adjust for each of the potential confounding factors previously listed. A two-way analysis of variance (ANOVA) with a post hoc test will be used to determine the relationship between timolol serum levels and wound healing. For demographic and clinical characteristic data at baseline, continuous variables will be summarized (when appropriate) by using mean, median, standard deviation, co-efficient of variation, minimum value, and maximum value. Categorical variables can be summarized with frequency tables. Baseline comparability between the two treatment groups will be assessed using the independent two-sample $t$-test or Wilcoxon rank-sum test and the Chi-square test or Fisher's exact test. Finally, we will use ANOVA to analyze quality of life (QOL) using the VR-36 Health Survey, the Lower Extremity Functional Scale outcome [39], and the Charlson Comorbidity Index [40]. For the analyses of the large number of multiple secondary outcomes, $p$-value adjustments will be performed by the procedure of Benjamini and Hochberg [41].

\section{Standard of care}

The weekly visits for all subjects (treatment and control groups) will consist of ulcer assessment, debridement or removal of necrotic/infected tissues, wound cleansing, dressing to maintain a moist wound environment, and management of wound infection. Ulcer area is to be measured using 3D-digital photography, Silhouette ${ }^{\bullet}$ Aranz camera, before and after sharp debridement of the ulcer. We will use offloading devices (such as orthotics, total contact casts, crutches, wheelchairs) to protect the wound from pressure or trauma relating to ambulation or other daily activities. Treatment for infection will be initiated if it is indicated. The weekly wound assessment is detailed in Table 2. During the initial workup, subjects will be assessed for adequate blood circulation with the anklebrachial index (ABI), and we will establish and provide nutritional support, which includes blood glucose control that would meet the criteria of the Food and Drug Administration (FDA) Guidance for Industry Chronic Cutaneous Ulcer and Burn Wounds as well as the International Best Practice Guidelines for wound management in DFUs [3].

\section{Specifications of study drug: Timoptic-XE ${ }^{\oplus}$}

Timolol has been used since the 1970s as a systemic blood pressure lowering agent and has a strong safety profile. It is a non-selective, reversible, beta-adrenergic receptor blocker [42]. Its uses include systemic treatment of hypertension, angina pectoris, cardiac arrhythmias, migraine, and the reduction of mortality following myocardial infarction [43]. It is also widely used as an ophthalmic solution in the treatment of glaucoma to reduce intraocular pressure $[44,45]$. Topically applied, timolol has also shown great success with a good safety profile as adjunct therapy for infantile hemangiomas in several countries around the world [46-54]. In fact, the FDA has now approved the use of a similar beta blocker, propranolol, as an oral pediatric formulation of propranolol hydrochloride (Hemangeol) for proliferating hemangioma [55, 56]; currently it is the most common form of therapy for children with ulcerated hemagiomas $[46-54,56]$. The drug to be used in this study is the commercially available ocular formulation of timolol, timolol maleate ophthalmic gel forming solution, which has been developed as an extended release preparation (Timoptic-XE, Merck \& Co, Inc.). In addition, the FDA has provided our investigative team with Investigational New Drug (IND) approval to safely proceed with the use of Timoptic-XE (timolol maleate ophthalmic gel forming solution, $0.5 \%$ for use on DFUs, IND number 122399). 


\begin{tabular}{|c|c|c|c|c|c|c|c|c|c|}
\hline Procedure & \multicolumn{2}{|c|}{$\begin{array}{l}\text { Screening Phase } \\
\text { Visits 1-2 (Week 1-2) }\end{array}$} & \multicolumn{2}{|c|}{$\begin{array}{l}\text { Active Phase } \\
\text { Visits 3-14 } \\
\text { (Week 3-14) } \\
\text { Including a 1st } \\
\text { confirmatory visitif } \\
\text { healed before } 12 \\
\text { weeks of treatment }\end{array}$} & \multirow{2}{*}{$\begin{array}{c}\text { 2nd } \\
\begin{array}{c}\text { Confirmatory } \\
\text { Visit }\end{array} \\
\text { Prior to Follow- } \\
\text { up } \\
\text { Phase } \\
\text { Visit 15 } \\
\text { (Week 15) } \\
\\
\\
\text { Visit 15 } \\
\text { (Week 15) }\end{array}$} & \multicolumn{4}{|c|}{$\begin{array}{l}\text { Follow-up Phase } \\
\text { Visits 16, } 17,18 \& 19 \\
\text { (Week 19, 23, } 27 \& 31 \text { ) }\end{array}$} \\
\hline & $\begin{array}{l}\text { Visit } 1 \\
\text { (Week } \\
\text { 1) }\end{array}$ & $\begin{array}{l}\text { Visit } 2 \\
\text { (Week } \\
\text { 2) }\end{array}$ & $\begin{array}{l}\text { Visit } 3 \\
\text { (Week } \\
3) \\
\text { Rando } \\
\text { mizatio } \\
n\end{array}$ & $\begin{array}{l}\text { Visits } \\
4-14 \\
\text { (Week } \\
4-14) \\
\text { Study } \\
\text { Endpo } \\
\text { int at } \\
\text { Week } \\
\text { 14* }^{*}\end{array}$ & & $\begin{array}{c}\text { Visit } \\
16 \\
\text { (Week } \\
19)\end{array}$ & \begin{tabular}{|l} 
Visit \\
17 \\
(Wee \\
k 23)
\end{tabular} & $\begin{array}{l}\text { Visit } \\
18 \\
\text { (Wee } \\
\text { k 27) }\end{array}$ & $\begin{array}{c}\text { Visit } 19 \\
\text { (Week } \\
\text { 31) }\end{array}$ \\
\hline $\begin{array}{l}\text { Inclusion/Exclus } \\
\text { ion Criteria }\end{array}$ & $x$ & $x$ & $x$ & & & & & & \\
\hline $\begin{array}{l}\text { Informed } \\
\text { Consent/HIPAA } \\
\text { document }\end{array}$ & $x$ & & & & & & & & \\
\hline \begin{tabular}{|l|} 
VR-36 Health \\
Survey \\
Questionnaire \\
Lower Extremity \\
Functional \\
Scale Outcome \\
Questionnaire
\end{tabular} & $x$ & & & $\mathrm{X}^{*}$ & & & & & \\
\hline $\begin{array}{l}\text { Physical Exam, } \\
\text { EKG }\end{array}$ & $x$ & & & $\mathrm{X}^{*}$ & & & & & \\
\hline \begin{tabular}{|l|} 
Vital Signs \\
\end{tabular} & $x$ & $x$ & $x$ & $x$ & $x$ & $x$ & $x$ & $x$ & $x$ \\
\hline \begin{tabular}{|l|} 
Ankle-Brachial \\
Index/Duplex \\
Scan
\end{tabular} & $x$ & & & & & & & & \\
\hline \begin{tabular}{|l|} 
Bacterial, \\
Fungal Infection \\
and Malignancy \\
Evaluation
\end{tabular} & $x$ & & & & & & & & \\
\hline \begin{tabular}{|l|} 
Laboratory \\
evaluation \\
(hematology, \\
renal, and liver \\
function)
\end{tabular} & $x$ & & & & & & & & \\
\hline $\begin{array}{l}\text { Blood Sample } \\
\text { for Timolol } \\
\text { assay† (weeks } \\
4,8,12 \text { ) }\end{array}$ & & & $x$ & $x^{+}$ & & & & & \\
\hline \begin{tabular}{|l|} 
Ulcer \\
Assessment
\end{tabular} & $x$ & $x$ & $x$ & $x$ & $x$ & $x$ & $x$ & $x$ & $x$ \\
\hline 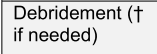 & $x$ & $x$ & $x$ & $x$ & $x^{+}$ & $x^{\dagger}$ & $\mathrm{X}^{\dagger}$ & $x^{\dagger}$ & $x^{+}$ \\
\hline \begin{tabular}{|l|} 
Ulcer \\
Photography \\
and Area \\
Measurement
\end{tabular} & $x$ & $x$ & $x$ & $x$ & $x$ & $\mathrm{x}$ & $x$ & $x$ & $x$ \\
\hline \begin{tabular}{|l|}
$\begin{array}{l}\text { Offloading } \\
\text { device }\end{array}$ \\
\end{tabular} & $x$ & $x$ & $x$ & $x$ & $x$ & $x$ & $x$ & $x$ & $x$ \\
\hline Randomization & & & $\mathrm{x}$ & & & & & & \\
\hline $\begin{array}{l}\text { SOC + } \\
\text { Timoptic-XE@ }\end{array}$ & & & $x$ & $x$ & & & & & \\
\hline \begin{tabular}{|l|} 
SOC + non \\
biologically \\
active gel \\
(hydrogel as \\
placebo \\
medication)
\end{tabular} & & & $x$ & $x$ & $x$ & $x$ & $x$ & $x$ & $x$ \\
\hline \begin{tabular}{|l|} 
Concomitant \\
Medications \\
and Adverse \\
Events
\end{tabular} & $x$ & $x$ & $x$ & $x$ & $x$ & $\mathrm{x}$ & $x$ & $x$ & $\mathrm{x}$ \\
\hline
\end{tabular}

Fig. 2 Study diagram

\section{Drug management and record keeping}

The Sacramento VA research pharmacist will receive and manage both the non-biologically active gel (placebo) and the Timoptic-XE ${ }^{\oplus}$. The pharmacist will randomize the patients between the two groups, using the website Randomization.com [57], and will dispense either the Timoptic-XE ${ }^{\oplus}$ or non-biologically active gel hydrogel to the patients according to the arms to which they have been randomized. The research pharmacist will obtain both the study drug and placebo medication from their respective manufacturers, and the study team will provide the research pharmacy with clear empty 


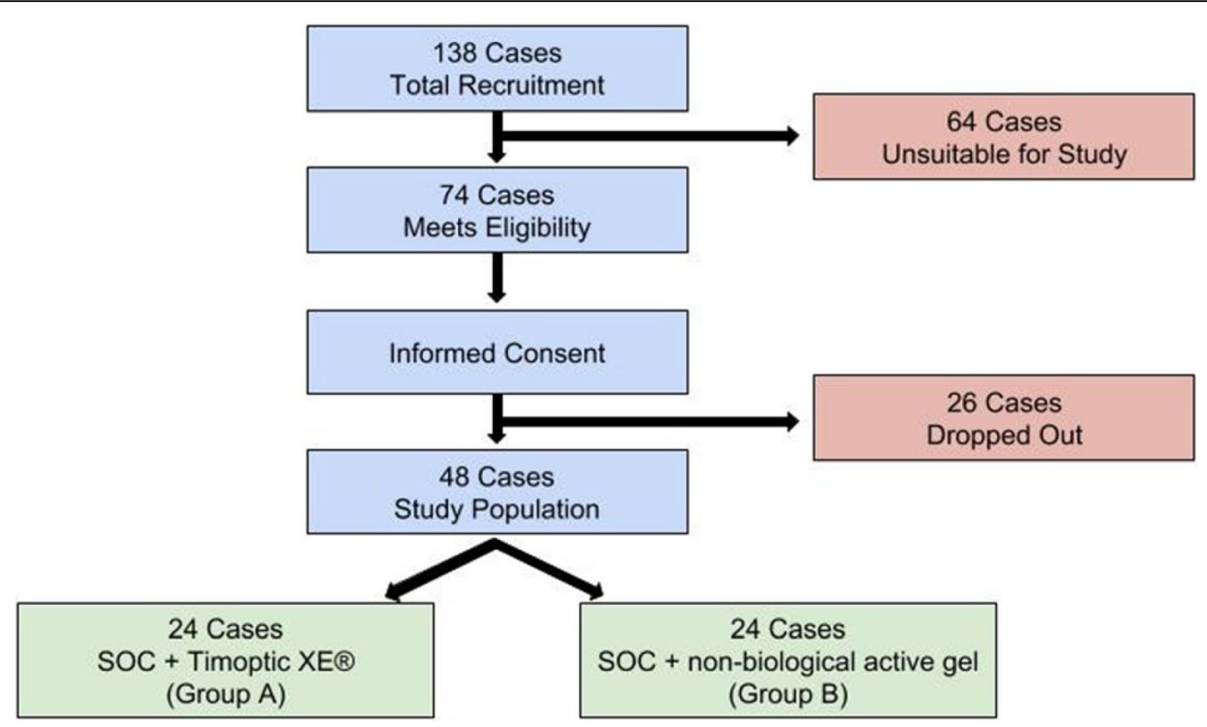

Fig. 3 Summary of selection process

identical dispensing bottles covered with amber bags to protect the drug from light. The pharmacist will employ Good Clinical Practice methods when transferring the active or placebo study drugs into the dispensing bottles. Once transferred, the bottles are placed into amber zip lock bags and labeled with the appropriate drug code and auxiliary labels. Subjects will be provided with 12 weeks' supply according to their individual randomized unique identifier to ensure accurate storage and dispensing records. The unblinded research pharmacist will keep a record of the drug and patient treatment group assignment.

The recommended Timoptic- $\mathrm{XE}^{\bullet}$ ocular dosage is 0.25 $\mathrm{mg} /$ day ( 1 drop in each eye once a day) $[49,58,59]$. The average exposed ocular surface is about $3 \mathrm{~cm}^{2}$ [32]. Based on the studies using timolol topically for ulcerative hemangiomas $[46-54,56,60]$ and the numerous case studies of topical timolol on chronic wounds [39, 40, 61, 62], the maximum dosage used in this study will be 3 drops $/ 3$ $\mathrm{cm}^{2} /$ day, which is equivalent to $0.75 \mathrm{mg} / 3 \mathrm{~cm}^{2} /$ day (Table 3). For study patients, depending on the size of the DFU, see Table 3, either topical timolol or placebo drug (non-biologically active gel) will be administered as one drop daily for $<0.5 \mathrm{~cm}^{2}$ to $>0.5-1.9 \mathrm{~cm}^{2}$, two drops daily for wound size $>2-2.9 \mathrm{~cm}^{2}$, and three drops daily for anything $>3 \mathrm{~cm}^{2}$ (maximum dose). Depending on the size of the wound, the research pharmacist will dispense one or two bottles (with either Timoptic-XE ${ }^{\bullet}$ or placebo) for the 12 weeks' supply as described in the table below.

\section{Selection of treatment site}

For subjects presenting with multiple wounds, the largest wound will be the index ulcer, and will be greater than $3 \mathrm{~cm}$ distance from any other ulcer. The index ulcer will be assessed and treated prior to all non-index ulcers to avoid cross-contamination. All non-index ulcers will be treated per physician discretion. The subject will be followed weekly in clinic visits and the evaluation and assessment of the ulcers will be performed as described below.

\section{Informed consent and enrollment}

This study will be conducted exclusively on veterans within the VANCHCS with a documented diagnosis of diabetes who have had a foot ulcer for at least 4 weeks. Patient recruitment and obtaining consent will be performed by the research team, which includes research investigators, a research coordinator, and a wound research fellow. Any information collected in this study will remain confidential and no identifying information will be released during this study. HIPAA guidelines will be followed. A unique study identifier (ID) will be assigned to participants and no personal information will be linked to patients.

Patients who meet the eligibility criteria, as described in Table 1, will be approached to participate in the study. Any potential subject that agrees to join the study will be provided with VA IRB approved informed consent/HIPAA documents. Research staff will provide a detailed description of the study purpose, procedures, duration, and potential risks, as described in Table 4. Each subject will be provided with adequate time to consider the information and ask any questions before signing the informed consent document. Subjects will be provided with a copy of their signed/dated informed consent and another copy will be kept as part of the subject's research study record; those subjects will be considered enrolled in the clinical trial, meeting all inclusion 
Table 2 Weekly assessment for all study participants

Ulcer assessment and measurement
- Consistency of wound edges, fibrin, peri-wound erythema, peri-
wound edema, peri-wound induration, qualitative quality of foot/leg
edema, granulation tissue, necrotic tissue (amount), exudate (type),
exudate (amount), wound size (cm²), pain and presence of
epithelialization
Lab tests per protocol
Sharp debridement
Wound cleansing and moist wound healing dressing
Digital photograph using the Silhouette Aranz camera
- Device that provides three-dimensional measurement and docu-
mentation of the wound surface area, depth and volume, along with
storage and wound informatics management, i.e., graphic depiction
of wound progression timeline
Infection/ osteomyelitis assessment if indicated with confirmatory
bacterial culture
- Deep swab curette, tissue specimen/biopsy), radiographs and blood
work (CBC, ESR, CRP, and chemistry). Note: if radiograph suggests but
does not confirm osteomyelitis, then follow-up studies of bone scan,
bone biopsy, or MRI or CT imaging will be obtained as deemed ne-
cessary by investigator clinician
Use of an offloading device that protects the wound from pressure or
trauma related to ambulation and other acts of daily living
- The total contact cast or instant total contact cast would be ideal
offloading devices. However, given the nature and complexities
associated with DFU, it is unrealistic to expect that all patients will
tolerate such offloading devices. Thus, the offloading device provided
will be dependent on the subject's ability to tolerate the specific
offloading device. Adherence to offloading device will be evaluated
by the investigator at each visit by observing plantar wear patterns
and inquiring from the patient if offloading was used consistently as
instructed. Alternative to total contact cast or instant total contact
cast (camwalker), offloading devices will be offered including, but not
limited to, the use of felt/foam adhesive/post op shoe, custom
offloading insole, and customized healing shoe in combination with
or motorized scooter.
Smoling as a roll-a-bout scooter, walker, wheelchair,

Note: Blood glucose monitoring/management will be addressed by the consultant endocrinologist for any patient with $\mathrm{HbA} 1 \mathrm{C}$ above 8

Group A: SOC plus Timoptic-XE ${ }^{\circledast}$. The subjects will receive the SOC treatment as described above plus Timoptic-XE

Group B: SOC plus non-biologically active gel (hydrogel, as placebo medication)

All other procedures are as in the SOC group and no exclusion criteria as they enter the screening phase.

\section{Randomization}

The Randomization.com website will be used for simple randomization allocation. It is a website programmed to perform randomization schemes through randomization plan generators. The specific randomization scheme for the BAART study randomizes 48 subjects to an active component and a placebo component. If the study exceeds the expected 48 targeted subjects for enrollment, the program can be altered so that the same scheme is generated to randomize additional subjects. Each subject will be given a unique identifier with no personal information linked after assignment according to a randomly computer generated listed of two repeated numbers for placement into either group A or group B. The research pharmacist will dispense either Timoptic-XE $\mathrm{X}^{\oplus}$ or the non-biologically active gel hydrogel to patients according to their randomized arm. Subject demographics will not be recorded until this assignment is complete. The patients will be blinded to study drug treatment.

\section{Study schematic \\ Enrollment}

All participants are screened for eligibility based on the inclusion and exclusion criteria. The eligible participants will be called by the research coordinator and invited to participate in the study (Fig. 2).

\section{Screening phase-2 weeks' duration (visits 1-2/weeks 1-2)}

Subjects will be screened to determine if they meet the inclusion and exclusion criteria requirements, and those with any clinical conditions that may contraindicate the use of the study drug are excluded from the study. Table 5 describes the workup performed in order to determine eligibility for this study. Subjects will receive comprehensive training on protocol-specified treatment application in order to determine their ability to comply with this study. Each subject will receive SOC as described previously (Table 2). At the completion of the 2-

Table 3 Timolol dosage management

\begin{tabular}{llllll}
\hline $\begin{array}{l}\text { Wound size } \\
\left(\mathrm{cm}^{2}\right)\end{array}$ & $\begin{array}{l}\text { Number of } \\
\text { drops }\end{array}$ & $\begin{array}{l}\text { Timolol dosage } \\
(\mathrm{mg} / \text { day })\end{array}$ & $\begin{array}{l}\text { Timolol dosage } \\
(\mathrm{mL} / \text { day) } \\
\text { Note: } 1 \text { drop }= \\
0.05 \mathrm{ml}\end{array}$ & $\begin{array}{l}\text { Dosage for 12-week } \\
\text { supply }(\mathrm{ml})\end{array}$ & $\begin{array}{l}\text { Number of bottles (timolol or placebo) dispensed to patient for } \\
\text { 12-week supply (1 bottle =5 ml) }\end{array}$ \\
\hline $\mathbf{0 . 5}$ & 1 & 0.25 & 0.05 & 4.2 & 1 \\
$>\mathbf{0 . 5 - 0 . 9}$ & 1 & 0.25 & 0.05 & 4.2 & 1 \\
$>\mathbf{1 . 0 - 1 . 9}$ & 1 & 0.25 & 0.05 & 4.2 & 1 \\
$>\mathbf{2 . 0 - 2 . 9}$ & 2 & 0.5 & 0.1 & 8.4 & 2 \\
$>\mathbf{3 . 0}$ & 3 & 0.75 & 0.15 & 12.6 & 3 \\
\hline
\end{tabular}


Table 4 Potential risks and adequacy of protection from risks

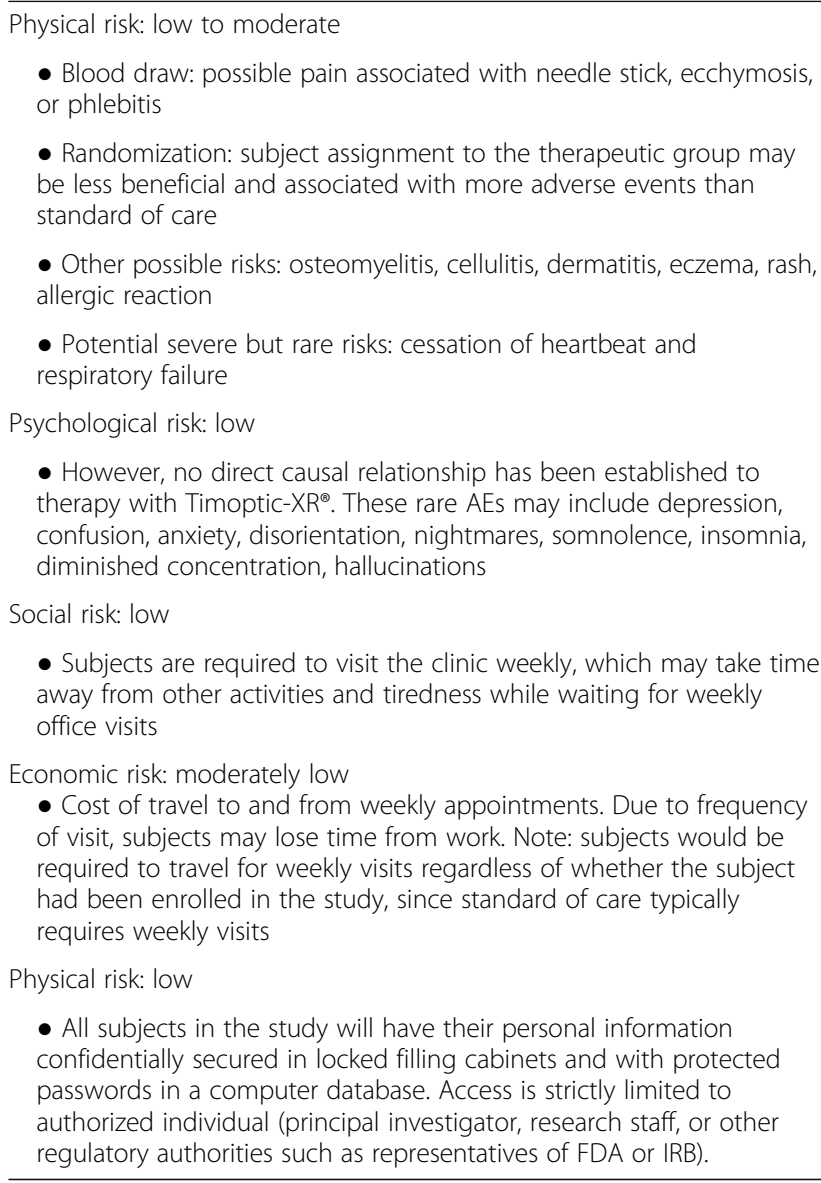

week screening phase, subjects who experience more than $40 \%$ change in ulcer size will be exited from the study prior to randomization (since they are not difficult-to-heal ulcers).

Active phase-12 weeks (visits 3-15/weeks 3-15)

Randomization visit (visit 3/week 3) Subjects who successfully meet the study requirements and complete the screening phase will be randomized into either group $\mathrm{A}$ (Timoptic-XE plus SOC) or group B (non-biological gel plus SOC). Subjects in group A will undergo the same SOC, including wound care and offloading modality, as individuals in group B. The placebo medication will be applied to the wound daily with the same dosage as above.

Treatment phase (visits 4-14/weeks 4-14) Subjects will be evaluated and receive treatments on a weekly basis (7 days \pm 2 days). The investigator (physician) will determine the time of wound closure, as defined by "skin reepithelialization" without drainage or dressing requirements confirmed at two consecutive study visits, 2 weeks apart. If the ulcer remains healed at the second confirmatory visit, the subject will proceed to the follow-up phase, i.e., these patients will skip any remaining visits in the active phase.

Blood samples will be taken from each subject at weeks 4,8 , and 12 to determine plasma timolol level. We do not anticipate blood levels in our patients to be higher than those seen in patients who receive Timoptic $\mathrm{XE}^{\oplus}$ gel for ocular indication (normal range $0.3-0.5 \mathrm{ng} / \mathrm{ml}$ ) [63]. Subjects in whom the timolol level is $0.7 \mathrm{ng} / \mathrm{ml}$ or higher will be removed from the study.

Study primary endpoint (visit 14/week 14) and 2nd confirmatory visit (visit 15/week 15) At the end of study treatment, the ulcer will be assessed for healing characteristics to determine if it has completely epithelialized; if there are concerns, further workup will be obtained and addressed accordingly. The subjects will also complete the health-related quality of life survey or the VR-36 Health Survey and the Lower Extremity Functional Scale Outcome Questionnaire.

\section{Follow-up phase (visit 16-19/week 19-31)}

Subjects will be seen for follow-up visits at monthly intervals for 4 months. Those subjects who have unhealed wounds at completion of the final study visit will continue with SOC at a regular wound clinic. At each follow-up visit an evaluation of the durability of wound closure of the study ulcer will be assessed by the clinician. Digital imaging of ulcer location of non-healed ulcer, study staff will be obtained pre- and postdebridement images. Any changes in concomitant medications, adverse events, or compliance with offloading will be recorded.

\section{Withdrawal}

Subjects may request to withdraw from the study at any time. The investigator may also remove a subject if it is determined that the subject develops serious adverse event (SAE) related to the study. A SAE is defined by the FDA as any adverse drug event that results in any of the following outcomes: death, life-threatening adverse events, inpatient hospitalization, or prolonged existing hospitalization for more than $24 \mathrm{~h}$ [64]. Intention-totreat analysis will be performed. Subjects who are withdrawn from the study will be followed via patient chart reviews from their regular wound care visits. Those subjects that have undergone treatment will be followed and documented until the end of the study. If there is more than $15 \%$ loss to follow-up, investigators will attempt to recruit additional subjects. 
Table 5 Screening assessments and pre-treatments

\begin{tabular}{|c|c|}
\hline Demographic information & Gender, age, race \\
\hline Medical history & Medical problems, surgeries, trauma, history of previous ulcers, amputations, characteristics, and duration \\
\hline $\begin{array}{l}\text { Comprehensive history and } \\
\text { physical exam }\end{array}$ & Vital signs, height, weight, body mass index \\
\hline General health and lifestyle & Smoking history, alcohol, drug abuse \\
\hline Lower extremity exam & $\begin{array}{l}\text { Vascular-pedal pulses, color of skin, temperature, edema. Dermatological_clinical description of the ulcer, fungal } \\
\text { infection of skin and/or nails, skin integrity (calluses, dryness). Musculoskeletal—foot deformities such as bunion, } \\
\text { hammertoe, bony prominence, fat pad atrophy, altered gait. Neurological_absence or presence of sensation with } \\
5.07 / 10 \text { Semmes-Weinstein monofilament, reflexes }\end{array}$ \\
\hline Non-invasive vascular study & $\begin{array}{l}\text { Ankle-brachial systolic pressure }(\mathrm{ABI}) \text { and toe-brachial systolic pressure (TBI). In order to meet criteria, ankle-arm } \\
\text { index must be equal to or greater than } 0.8 \text { and less than } 1.4 \text { or a toe-arm index is equal to or greater than } 0.6\end{array}$ \\
\hline Foot ulcer history & Location, length of time, treatments used, pain, etiology of ulcer \\
\hline Laboratory & $\begin{array}{l}\text { Hematology, chemistry, EKG, microbiology and pathology } \mathrm{HbA1c} \text {, pregnancy test (for women of childbearing } \\
\text { ages), LFT, ESR, CRP, and albumin }\end{array}$ \\
\hline Radiological imaging & Plain foot and/or ankle films for baseline \\
\hline Health—quality of life surveys & VR-36 Health Survey and the Lower Extremity Functional Scale Outcome Questionnaire \\
\hline $\begin{array}{l}\text { Debridement and specimen } \\
\text { collection }\end{array}$ & $\begin{array}{l}\text { Sharp debridement of ulcer will be performed per standard method. A small sample will be collected for } \\
\text { microbiology (gram stain, cultures/sensitivities, and fungal) and pathology }\end{array}$ \\
\hline Photographs & Before and after debridement using Silhouette Mobile ${ }^{T M}$ ulcer tracing, surface area calculation \\
\hline Dressings & Non-adhesive dressing (Adaptic ${ }^{\circledast}$ or Mepite ${ }^{\circledR}$ ) over wound bed, covered by dry dressings \\
\hline Off-loading & $\begin{array}{l}\text { Shoes will be given, modified offloading insert (trilaminar plastazote) as determined appropriate at the discretion } \\
\text { of the clinician }\end{array}$ \\
\hline
\end{tabular}

\section{Non-compliance}

During the screening period, one-to-one training will be given to ensure that the subjects are able to apply the medication and proper dressing as per the protocol. A unique challenge may be related to the application of the offloading device. We propose to prevent this potential problem by providing the opportunity for subjects to return to the clinic the same day if they feel that the offloading device needs to be adjusted prior to the next scheduled appointment. We will provide subjects with monetary compensation at the end of the active phase, and then the remaining compensation will be given at the end of the study (upon completion of the follow-up phase).

\section{Loss to follow-up}

Our clinical research staff will phone each patient prior to their appointment days to keep communication lines open. If patients are unable to visit our clinic for a particular scheduled visit, our staff will reschedule to accommodate his/her schedule in a \pm 7 -day window and perform all study-related functions for that visit.

\section{Blinding/breaking the blind}

The active and placebo study drugs will be received from the manufacturer by the research pharmacist, who will repackage them in coded dropper dispenser bottles. Since the drug and placebo will be repackaged into identical dispensers, investigators, research staff members, including the research coordinator, research fellow, sponsors, and study subjects, will be blinded to the study treatment.

In the event of any SAEs related to the study, the investigator will break the blind [65]. In addition, the DSMB will regularly review the obtained research data and will trigger modifications to the trial or the management of an individual subject should SAEs arise. The DSMB, located at Hines VA Hospital, 60,141, IL, USA, is independent of the sponsor, competing interests, and of our local facility.

\section{Adverse events}

All adverse events (AEs) that occur during the course of the study will be noted and documented by type, seriousness, intensity/grade, relationship to diabetes, and the unique therapy. All AEs will be reported to the principle investigator. Each week, the study investigator will review the $\mathrm{AE}$ forms from the previous week for any new or continuing events. A study participant may have their medication discontinued or may be withdrawn from the study if the medically responsible investigator determines it is the best decision in order to protect the safety of the participant.

At each visit, the investigator will clinically assess the subject's wound for infection. The presence of moderate or severe signs/symptoms of inflammation [66] will prompt further laboratory evaluation (i.e., hematology, wound culture). Infected ulcers will result in study exit and an appropriate documentation of the AEs and 
treatment per protocol. Also, the DSMB will monitor the study and provide guidance if AEs are noted. The DSMB will regularly review the obtained research data and will trigger modifications in the trial or in the management of an individual subject should SAE arise.

\section{Analysis \\ Sample size estimation and randomization}

From previous studies [11, 18, 19], we expect that about $20 \%$ of the study subjects will heal in the control arm of our study by the 12th week of care. We estimate that the experimental treatment will improve this outcome with $63 \%$ of the study subjects healing by the 12 th week of care (a healing rate close to that reported in the most recent case series of topical use of timolol on chronic wounds [67]). We will perform simple randomization of the subjects using electronic randomization for treatment assignment since our target enrollment population is fairly homogenous.

The sample size calculation requires the enrollment of 48 subjects (24 subjects in each arm) to provide statistical power of $80 \%$ to detect a difference of $43 \%$ (63\% $20 \%$ ) in the rate of ulcer healing between the two arms using two-sided Fisher's exact test at a significance level of $5 \%$. It is estimated that the overall attrition will be $35 \%$. Specifically, $10 \%$ of the subjects who are enrolled will be exited from the study prior to randomization, $10 \%$ will not meet the primary endpoint analysis inclusion requirement, and $15 \%$ will not complete the study due to other factors such as treatment failure, loss to follow-up, adverse events, clinical/safety issues, and/or non-compliance. We will track the various reasons for study exit. Therefore, 138 subjects (69 subjects in each arm) will be recruited into the study. After taking into account an overall attrition of $35 \%$, a total of 48 patients will be enrolled in the study. The consulting statistician will review implementation and compare major baseline demographic and prognostic characteristics to ascertain that randomization was successful. The power analysis was formulated using the STPLAN version 4.5 (2010) [68] with the input of the study consultant biostatistician. When study is at the midpoint, interim analysis will be performed to assess for the primary outcome for the two study treatment groups.

\section{Data management plan}

The primary outcome analyses will be performed on an intent-to-treat basis. The analysis of subjects will be done per study group regardless of missing data from subjects who did not complete the study. We will impute missing data by using multiple imputation techniques in the analyses.

All of the patient's data will be securely stored in locked cabinets per the VA protocol and in secure VA servers that provide centralized file storage and backup, and they will only be accessible by the research staff. The final data and results from the study will be shared via publication. Electronic datasets will be de-identified and anonymized. These datasets will be maintained locally on VA protected servers until enterprise-level resources become available for long-term storage and retrieval.

\section{Discussion}

This is a clinical translation study, moving the investigators' pre-clinical laboratory research into the first randomized clinical study. Our previous work has demonstrated that stress-catecholamines such as epinephrine and norepinephrine, $\beta A R$ agonists, impair wound healing as evidenced by decreased keratinocyte migration and a decrease in keratinocytes' ability to heal wounds in vitro [23, 27, 28, 31, 33, 34]. Interestingly, not only can stress-induced elevation of systemic catecholamines impair healing [69, 70], but as we and others have shown, the keratinocytes themselves can generate epinephrine [25, 71] and significant levels of catecholamines are present within the immediate vicinity of the wound [24]. Conversely, our laboratory investigations have shown that $\beta A A s$ increase keratinocyte migration speed (a surrogate for epithelial healing), the healing of scratch wounds in confluent keratinocyte cultures [31], and wound epithelialization in vivo in a number of animal wound models [24, 26, 28, 72]. Additionally, in a human skin ex vivo burn wound model, cultivation with $\beta A A$ (timolol) improves wound re-epithelialization relative to the culture medium control. Further, our studies have shown that catecholamines increase neutrophil dwell time in the wound, delaying healing in an animal wound model, and treatment with $\beta A A$ reverses this, restoring healing time to normal [73]. We and others have also documented and reported on cases of venous leg ulcers and other chronic wounds in humans that have improved healing after topical timolol application [38, 61, $62,67]$. These multiple laboratory studies and anectdotal clinical reports indicate that $\beta A A s$ (timolol) promote wound healing and shorten time to healing; thus, a clinical trial is the next logical step to determine if this approach is truly efficacious in the clinical setting of DFUs.

We hypothesized that subjects with DFU treated with a BAA (timolol) will have more rapid complete wound closure compared to those in the SOC group. The null hypothesis is that there is no difference in the proportion of subjects with complete wound closure of DFUs between the two treatment arms.

The Cochrane Wounds Group has indicated that the healing rates and healing time commonly reported in the majority of wound studies and clinical trials area deemed appropriate primary outcomes [74]. In fact, 
most studies have demonstrated that the proportion of ulcers healed at 12 weeks of treatment is an appropriate outcome measure $[18,19]$. Thus, for our study purposes, the primary endpoint is complete ulcer closure as defined by "skin re-epithelialization without drainage or dressing requirements" by week 12 (end of the active phase of the study).

We will also assess secondary endpoints that will focus on measurements obtained throughout the clinical trial, including change in percentage reduction in wound size between the two study arms, calculated as difference in $\mathrm{cm}^{2}$ of the randomization measurement after 12 weeks of the active phase and after the follow-up phase. We will consider patient's quality of life using the VR-36 Health Survey, the Lower Extremity Functional Scale [39], and the Charlson Comorbidity Index [40].

AEs will be assessed for safety parameters that specifically include SAEs, hospitalization, study exit, unanticipated adverse device effects, and therapy-related incidences. We will analyze and compare the data between these two treatment arms, including AEs at an incidence of $1 \%$ or greater, adverse reactions to the test therapy at an incidence of $1 \%$ or greater, incidence of immediate reactions, incidence of local and systemic reactions, incidence of osteomyelitis, incidence of wound infection, and incidence of SAEs or unanticipated adverse device effects. Potential confounding variables include Basic Metabolic Index (BMI), wound size (which we will adjust for using the subcategories $<0.4 \mathrm{~cm}^{2}$, > $\left.0.5-0.9 \mathrm{~cm}^{2},>1.0-1.9 \mathrm{~cm}^{2},>2.0-2.9 \mathrm{~cm}^{2},>3.0 \mathrm{~cm}^{2}\right)$, as well chronicity of the wound by year (adjusted for using $<1$ year, > $1-3$ years, $>3-5$ years, $>5$ years, > 10 years). Safety data collected from the clinical trial will significantly contribute toward establishing the safety profile of topical $\beta$ AA use in DFUs.

There may be several potential limitations to this study involving study subjects' demographics. As this study occurs solely at veteran medical centers, there may be bias for recruiting mainly veteran male patients. Compared to the US general population ( $49 \%$ male, $50 \%$ female), females represent only $9 \%$ of the veteran population nationwide $[9,75]$. Similarly, there may also be bias toward recruiting middle-age, elderly, and white veterans at the Veteran Health System [76], but it should be noted that DFUs are more common between the ages of 60 and 80 years $[2,4,5,8,14-16,55,77]$.

\section{Trial status}

Protocol date and version: December 5, 2019, version 4.

Patient recruitment began in August 2018 at the Sacramento VA Medical Center, Mather, CA, USA. Study enrollment and recruitment are estimated to be completed within 4 years.

\section{Abbreviations}

DFU: Diabetic foot ulcer; $\beta A A$ : Beta-adrenergic antagonists; $\beta A R$ : Betaadrenergic receptors; MSC: Mesenchymal stem cells; IRB: Institutional review board; SOC: Standard of care; FDA: Food and Drug Administration; ABI: Ankle brachial index; DSMB: Data and safety monitoring board; AE: Adverse events; ANOVA: Analysis of variance; QOL: Quality of life; VR-36: Veterans Rand-36; BMI: Basic Metabolic Index; VA: Veterans Affairs

\section{Acknowledgements}

We acknowledge the work of the Isseroff lab group at UC Davis that generated the bench data that support this clinical trial and we also acknowledge research pharmacist Dr. Kao Chang for her contribution to the randomization and preparation of study drugs.

\section{Authors' contributions}

$\mathrm{SD}$ is the principal investigator and RR is the co-principal investigator. All authors contributed to the design and development of this study protocol. SD, $R R, C T$, and $K W$ were responsible for receiving ethics approval and writing the original study protocol. RK wrote the first draft of this manuscript; all authors were involved in critically revising the manuscript for important intellectual content. All authors read and approved the final manuscript. All named authors adhere to the authorship guidelines of Trials. All authors have agreed to publication.

\section{Funding}

VA Merit Grant Award \# eRA\#: 1-IO1-CX-001503-01-A1.

This is a VA Merit-funded clinical trial. The study design and collection analysis were written and designed by the principle investigator and co-

investigator. The funding body has no contribution to the design or writing of the study. Also, the funding body will have no role in data collection, analysis, interpretation of the data, and writing of the manuscript. DSMB committee is a VA entity and it is independent of the sponsor and has no competing interests.

\section{Availability of data and materials}

A copy of the informed consent or dataset analyzed during the current study are available from the corresponding author on reasonable request.

\section{Ethics approval and consent to participate}

Study approval was obtained from the IRB Human Studies Subcommittee at the Sacramento VA Medical Center (reference [17]-08-00792) on August 16, 2017. Any protocol or informed consent amendments will require the IRB's approval. Routine auditing of this study will be performed by the Research Compliance Officer according to VA guidelines. All auditing will be independent of the investigators and the sponsor. The protocol identification number on ClinicalTrials.gov is NCT03282981. This study will be conducted in accordance with the medical professional codex and the Helsinki Declaration as of 1996 as well as Data Security Laws and Good Clinical Practice criteria.

Written IRB-approved informed consent will be obtained from all subjects prior to enrollment, and subjects will be given adequate time to declare if they wish to participate in this study before signing the consent form. Study participation is voluntary and can be withdrawn at any time without provision of reason and without negative consequences for future medical care.

Consent for publication

Not applicable.

\section{Competing interests}

The authors declare that they have no competing interests.

\section{Author details}

'Dermatology Service, VA Northern California Health Care System, Mather, CA, USA. ${ }^{2}$ Department of Dermatology, UC Davis Medical Center, Sacramento, CA, USA. ${ }^{3}$ Podiatry Service, VA Northern California Health Care System, Mather, CA, USA. ${ }^{4}$ Department of Internal Medicine, UC Davis Medical Center, Sacramento, CA, USA. 
Received: 28 October 2019 Accepted: 14 May 2020 Published online: 08 June 2020

\section{References}

1. Meijer JW, Trip J, Jaegers SM, Links TP, Smits AJ, Groothoff JW, et al. Quality of life in patients with diabetic foot ulcers. Disabil Rehabil. 2001;23(8):33640.

2. Santema TB, Poyck PP, Ubbink DT. Skin grafting and tissue replacement for treating foot ulcers in people with diabetes. Cochrane Database Syst Rev. 2016;2:CD011255.

3. International W. International Best Practices Guidelines: Wound management in diabetic foot ulcers 2013 [Available from: https://www. woundsinternational.com/resources/details/best-practice-guidelines-woundmanagement-diabetic-foot-ulcers. Accessed Feb 2020.

4. Fortington LV, Geertzen JH, van Netten JJ, Postema K, Rommers GM, Dijkstra PU. Short and long term mortality rates after a lower limb amputation. Eur J Vasc Endovasc Surg. 2013;46(1):124-31.

5. Armstrong DG, Wrobel J, Robbins JM. Guest Editorial: are diabetes-related wounds and amputations worse than cancer? Int Wound J. 2007;4(4):286-7.

6. Mayfield JA, Reiber GE, Maynard C, Czerniecki J, Sangeorzan B. The epidemiology of lower-extremity disease in veterans with diabetes. Diabetes Care. 2004;27(Suppl 2):B39-44.

7. Reiber GE, Koepsell TD, Maynard C, Haas LB, Boyko EJ. Diabetes in nonveterans, veterans, and veterans receiving Department of Veterans Affairs health care. Diabetes Care. 2004;27(Suppl 2):B3-9.

8. Association TAD. 2016 [Available from: https://professional.diabetes.org/ content/fast-facts-data-and-statistics-about-diabetes. Accessed Feb 2020.

9. National Center for Veterans Analysis and Statistics [Internet]. 2016. Available from: https://www.va.gov/vetdata/. Accessed Feb 2020.

10. Dubois W. Not your granddaddy's VA - Changing diabetes care for veterans: Healthline; 2012 [Available from: https://www.healthline.com/diabetesmine/ not-your-granddaddys-va-changing-diabetes-care-for-veterans\#1. Accessed Feb 2020 .

11. Boyko EJ, Ahroni JH, Stensel V, Forsberg RC, Davignon DR, Smith DG. A prospective study of risk factors for diabetic foot ulcer. The Seattle Diabetic Foot Study. Diabetes Care. 1999;22(7):1036-42.

12. Raghav A, Khan ZA, Labala RK, Ahmad J, Noor S, Mishra BK. Financial burden of diabetic foot ulcers to world: a progressive topic to discuss always. Ther Adv Endocrinol Metab. 2018;9(1):29-31.

13. Cavanagh P, Attinger C, Abbas Z, Bal A, Rojas N, Xu ZR. Cost of treating diabetic foot ulcers in five different countries. Diabetes Metab Res Rev. 2012;28(Suppl 1):107-11.

14. Boulton AJ. The diabetic foot: grand overview, epidemiology and pathogenesis. Diabetes Metab Res Rev. 2008;24(Suppl 1):S3-6.

15. Singh N, Armstrong DG, Lipsky BA. Preventing foot ulcers in patients with diabetes. JAMA. 2005:293(2):217-28.

16. Vuorisalo S, Venermo M, Lepantalo M. Treatment of diabetic foot ulcers. J Cardiovasc Surg. 2009;50(3):275-91.

17. de Groot AC, van Ginkel CJ, Bruynzeel DP, Smeenk G, Conemans JM. Contact allergy to eyedrops containing beta-blockers. Ned Tijdschr Geneeskd. 1998;142(18):1034-6.

18. Margolis DJ, Allen-Taylor L, Hoffstad O, Berlin JA. Diabetic neuropathic foot ulcers: the association of wound size, wound duration, and wound grade on healing. Diabetes Care. 2002;25(10):1835-9.

19. Margolis DJ, Gelfand JM, Hoffstad O, Berlin JA. Surrogate end points for the treatment of diabetic neuropathic foot ulcers. Diabetes Care. 2003;26(6): 1696-700.

20. Schallreuter KU. Epidermal adrenergic signal transduction as part of the neuronal network in the human epidermis. J Investig Dermatol Symp Proc. 1997;2(1):37-40

21. Steinkraus $V$, Steinfath $M$, Korner $C$, Mensing $H$. Binding of beta-adrenergic receptors in human skin. J Invest Dermatol. 1992;98(4):475-80.

22. Steinkraus V, Mak JC, Pichlmeier U, Mensing H, Ring J, Barnes PJ. Autoradiographic mapping of beta-adrenoceptors in human skin. Arch Dermatol Res. 1996;288(9):549-53.

23. Chen J, Hoffman BB, Isseroff RR. Beta-adrenergic receptor activation inhibits keratinocyte migration via a cyclic adenosine monophosphate-independent mechanism. J Invest Dermatol. 2002;119(6):1261-8.

24. Sivamani RK, Pullar CE, Manabat-Hidalgo CG, Rocke DM, Carlsen RC, Greenhalgh DG, et al. Stress-mediated increases in systemic and local epinephrine impair skin wound healing: potential new indication for beta blockers. PLoS Med. 2009;6(1):e12.

25. Dasu MR, Ramirez SR, La TD, Gorouhi F, Nguyen C, Lin BR, et al. Crosstalk between adrenergic and toll-like receptors in human mesenchymal stem cells and keratinocytes: a recipe for impaired wound healing. Stem Cells Transl Med. 2014;3(6):745-59.

26. Pullar CE, Le Provost GS, O'Leary AP, Evans SE, Baier BS, Isseroff RR. beta2AR antagonists and beta2AR gene deletion both promote skin wound repair processes. J Invest Dermatol. 2012;132(8):2076-84.

27. Pullar CE, Manabat-Hidalgo CG, Bolaji RS, Isseroff RR. beta-Adrenergic receptor modulation of wound repair. Pharmacol Res. 2008;58(2):158-64

28. Sivamani RK, Shi B, Griffiths E, Vu SM, Lev-Tov HA, Dahle S, et al. Acute wounding alters the beta2-adrenergic signaling and catecholamine synthetic pathways in keratinocytes. J Invest Dermatol. 2014;134(8): 2258-66.

29. Gurtner GC, Werner S, Barrandon Y, Longaker MT. Wound repair and regeneration. Nature. 2008;453(7193):314-21.

30. Pullar CE, Grahn JC, Liu W, Isseroff RR. Beta2-adrenergic receptor activation delays wound healing. FASEB J. 2006;20(1):76-86.

31. Pullar CE, Rizzo A, Isseroff RR. beta-Adrenergic receptor antagonists accelerate skin wound healing: evidence for a catecholamine synthesis network in the epidermis. J Biol Chem. 2006;281(30):21225-35.

32. Sivamani RK, Lam ST, Isseroff RR. Beta adrenergic receptors in keratinocytes. Dermatol Clin. 2007:25(4):643-53.

33. Raja, Sivamani K, Garcia MS, Isseroff RR. Wound re-epithelialization: modulating keratinocyte migration in wound healing. Front Biosci. 2007;12:2849-68.

34. Ghoghawala SY, Mannis MJ, Pullar CE, Rosenblatt MI, Isseroff RR. Beta2adrenergic receptor signaling mediates corneal epithelial wound repair. Invest Ophthalmol Vis Sci. 2008;49(5):1857-63.

35. Pullar CE, Isseroff RR. Beta 2-adrenergic receptor activation delays dermal fibroblast-mediated contraction of collagen gels via a CAMP-dependent mechanism. Wound Repair Regen. 2005;13(4):405-11.

36. Lindenschmidt RC, Witschi HP. Propranolol-induced elevation of pulmonary collagen. J Pharmacol Exp Ther. 1985;232(2):346-50.

37. Gulcan E, Kucuk A, Cayci K, Tosun M, Emre H, Koral L, et al. Topical effects of nebivolol on wounds in diabetic rats. Eur J Pharm Sci. 2012;47(2):451-5.

38. Lev-Tov H, Dahle S, Moss J, Isseroff RR. Successful treatment of a chronic venous leg ulcer using a topical beta-blocker. J Am Acad Dermatol. 2013; 69(4):e204-5.

39. Binkley JM, Stratford PW, Lott SA, Riddle DL. The Lower Extremity Functional Scale (LEFS): scale development, measurement properties, and clinical application. North American Orthopaedic Rehabilitation Research Network. Phys Ther. 1999;79(4):371-83.

40. Quan H, Li B, Couris CM, Fushimi K, Graham P, Hider P, et al. Updating and validating the Charlson comorbidity index and score for risk adjustment in hospital discharge abstracts using data from 6 countries. Am J Epidemiol. 2011;173(6):676-82.

41. Benjamini $Y$, Hochberg Y. Controlling the false discovery rate: a pratical and powerful approach to mulitple testing. JR Stat Soc Series B Stat Methodol. 1995;57:289-300.

42. Merck Sharp \& Dohme Research Laboratories. TIMOPTIC (timolol maleate) [package insert]. 2005. https://www.merck.com/product/usa/pi_circulars/t/ timoptic/timoptic optsol_pi.pdf. Accessed Feb 2020.

43. Khan N, McAlister FA. Re-examining the efficacy of beta-blockers for the treatment of hypertension: a meta-analysis. CMAJ. 2006;174(12):1737-42.

44. Zimmerman TJ, Kaufman HE. Timolol, dose response and duration of action. Arch Ophthalmol. 1977;95(4):605-7.

45. Uusitalo RJ, Palkama A. Long-term evaluation of timolol. Acta Ophthalmol. 1989;67(5):573-81

46. Pope E, Chakkittakandiyil A. Topical timolol gel for infantile hemangiomas: a pilot study. Arch Dermatol. 2010;146(5):564-5.

47. Ni N, Langer $P$, Wagner $R$, Guo S. Topical timolol for periocular hemangioma: report of further study. Arch Ophthalmol. 2011;129(3):377-9.

48. Oranje AP, Janmohamed SR, Madern GC, de Laat PC. Treatment of small superficial haemangioma with timolol $0.5 \%$ ophthalmic solution: a series of 20 cases. Dermatology. 2011;223(4):330-4.

49. Moehrle M, Leaute-Labreze C, Schmidt V, Rocken M, Poets CF, Goelz R. Topical timolol for small hemangiomas of infancy. Pediatr Dermatol. 2013; 30(2):245-9.

50. Chakkittakandiyil A, Phillips R, Frieden IJ, Siegfried E, Lara-Corrales I, Lam J, et al. Timolol maleate $0.5 \%$ or $0.1 \%$ gel-forming solution for infantile 
hemangiomas: a retrospective, multicenter, cohort study. Pediatr Dermatol. 2012;29(1):28-31.

51. Chambers CB, Katowitz WR, Katowitz JA, Binenbaum G. A controlled study of topical $0.25 \%$ timolol maleate gel for the treatment of cutaneous infantile capillary hemangiomas. Ophthalmic Plast Reconstr Surg. 2012;28(2): 103-6.

52. Semkova K, Kazandjieva J. Topical timolol maleate for treatment of infantile haemangiomas: preliminary results of a prospective study. Clin Exp Dermatol. 2013;38(2):143-6.

53. Chan H, McKay C, Adams S, Wargon O. RCT of timolol maleate gel for superficial infantile hemangiomas in 5- to 24-week-olds. Pediatrics. 2013 131(6):e1739-47.

54. Admani S, Feldstein S, Gonzalez EM, Friedlander SF. Beta blockers: an innovation in the treatment of infantile hemangiomas. J Clin Aesthet Dermatol. 2014;7(7):37-45.

55. Falanga $\mathrm{V}$. Wound healing and its impairment in the diabetic foot. Lancet. 2005;366(9498):1736-43.

56. Chen TS, Eichenfield LF, Friedlander SF. Infantile hemangiomas: an update on pathogenesis and therapy. Pediatrics. 2013;131(1):99-108.

57. Randomization. 2007. http://randomization.com/. Accessed Feb 2020.

58. Vlasses PH, Ribeiro LG, Rotmensch HH, Bondi JV, Loper AE, Hichens M, et al. Initial evaluation of transdermal timolol: serum concentrations and betablockade. J Cardiovasc Pharmacol. 1985;7(2):245-50.

59. Korte JM, Kaila T, Saari KM. Systemic bioavailability and cardiopulmonary effects of 0.5\% timolol eyedrops. Graefes Arch Clin Exp Ophthalmol. 2002;240(6):430-5.

60. Brooks M. FDA Oks Propanolol hydrochloride for infantile hemangioma 2014 [Available from: https://www.medscape.com/viewarticle/822115. Accessed Feb 2020.

61. Tang JC, Dosal J, Kirsner RS. Topical timolol for a refractory wound. Dermatol Surg. 2012;38(1):135-8.

62. Manahan MN, Peters P, Scuderi S, Surjana D, Beardmore GL. Topical timolol for a chronic ulcer--a case with its own control. Med J Aust. 2014;200(1):49-50.

63. Gallegos AC, Davis MJ, Tchanque-Fossuo CN, West K, Eisentrout-Melton A, Peavy TR, et al. Absorption and safety of topically applied timolol for treatment of chronic cutaneous wounds. Adv Wound Care (New Rochelle). 2019;8(11):538-45.

64. FDA. What is a Serious Adverse Event? Food and Drugs. https://www.fda. gov/safety/reporting-serious-problems-fda/what-serious-adverse-event. Accessed Feb 2020. Revised February 1, 2016.

65. Chin RL, B. Priniciples and practice of clinical trial medicine London. England: Academic press; 2008.

66. Lipsky BA, Berendt AR, Deery HG, Embil JM, Joseph WS, Karchmer AW, et al, Diagnosis and treatment of diabetic foot infections. Clin Infect Dis. 2004; 39(7):885-910.

67. Braun LR, Lamel SA, Richmond NA, Kirsner RS. Topical timolol for recalcitrant wounds. JAMA Dermatol. 2013;149(12):1400-2.

68. STPLAN: Double precision study planning calculations [Internet]. 2010 [cited 2019]. Available from: https://biostatistics.mdanderson.org/SoftwareDownload/.

69. Padgett DA, Marucha PT, Sheridan JF. Restraint stress slows cutaneous wound healing in mice. Brain Behav Immun. 1998;12(1):64-73.

70. Kiecolt-Glaser JK, Marucha PT, Malarkey WB, Mercado AM, Glaser R. Slowing of wound healing by psychological stress. Lancet. 1995;346(8984):1194-6.

71. Schallreuter KU, Wood JM, Lemke R, LePoole C, Das P, Westerhof W, et al. Production of catecholamines in the human epidermis. Biochem Biophys Res Commun. 1992;189(1):72-8.

72. Pullar CE, Zhao M, Song B, Pu J, Reid B, Ghoghawala S, et al. Beta-adrenergic receptor agonists delay while antagonists accelerate epithelial wound healing: evidence of an endogenous adrenergic network within the corneal epithelium. J Cell Physiol. 2007;211(1):261-72.

73. Kim MH, Gorouhi F, Ramirez S, Granick JL, Byrne BA, Soulika AM, et al. Catecholamine stress alters neutrophil trafficking and impairs wound healing by beta2-adrenergic receptor-mediated upregulation of IL-6. J Invest Dermatol. 2014;134(3):809-17.

74. Bell-Syer SE, Foxlee RE, Cullum NA. The Cochrane Wounds Group: systematically reviewing the wound care literature. Adv Skin Wound Care. 2007;20(5):283-7.

75. US general population male/female census [Internet]. 2018. Available from: https://www.census.gov/quickfacts/fact/table/US/pst045218. Accessed Feb 2020.

76. Veteran Health System. 2016 [Internet]. [cited 2019]. Available from: https:// www.va.gov/vetdata/.
77. Brem H, Tomic-Canic M. Cellular and molecular basis of wound healing in diabetes. J Clin Invest. 2007;117(5):1219-22.

\section{Publisher's Note}

Springer Nature remains neutral with regard to jurisdictional claims in published maps and institutional affiliations.
Ready to submit your research? Choose BMC and benefit from:

- fast, convenient online submission

- thorough peer review by experienced researchers in your field

- rapid publication on acceptance

- support for research data, including large and complex data types

- gold Open Access which fosters wider collaboration and increased citations

- maximum visibility for your research: over $100 \mathrm{M}$ website views per year

At BMC, research is always in progress.

Learn more biomedcentral.com/submissions 